\title{
TOOLS FOR CHILDREN FITNESS IN THE PHYSICAL EDUCATION OF PRIMARY SCHOOL PUPILS
}

\author{
Olga Rymar \\ Lviv State University of Physical Culture named after Ivan Boberskij, Ukraine \\ Alla Solovey \\ Lviv State University of Physical Culture named after Ivan Boberskij, Ukraine
}

Nataliya Sorokolit

Lviv State University of Physical Culture named after Ivan Boberskij, Ukraine

Uliana Shevtsiv

Lviv State University of Physical Culture named after Ivan Boberskij, Ukraine

\section{Vasyl Matviiv}

Lviv State University of Physical Culture named after Ivan Boberskij, Ukraine

\begin{abstract}
The results of pedagogical experiment that lasted from 2017 to 2018 are published in this research. 82 children took part in the experiment, among them were 42 boys and 40 girls. The actual age of children was nine years old. The purpose of the work was to discover the influence of fitness tools on physical development, physical preparation, psycho-emotional condition on younger school-age pupils. There was noticed a significant improvement of results of physical development according to Kettle index. In particular, it is about high level (from $16,9 \%$ to $43,1 \%$ ), decreasing the average (from $54,4 \%$ to $46,8 \%$ ) and especially the low level of physical development (from $28,7 \%$ to $10,1 \%),(p<0,05)$. Probably, positive changes appeared in the result of Ruffier Dickson tests, improvement indicators of intermediate level (from 4,8\% to $14,1 \%),(p<0,05)$, decreasing in indicators of lower-intermediate level (from $38,4 \%$ to $16,7 \%),(p<0,05)$. The stable dynamics was noticed in the results of physical preparation $(p<0,05)$, in particular after " $30 \mathrm{~m}$ run" exercise. Boys have got the result from $6,2 \pm 0,7 \mathrm{sec}$ to $5,4 \pm 0,5 \mathrm{sec}$, girls - from 6,9 $\pm 0,5 \mathrm{sec}$ to $6,1 \pm 0,5 \mathrm{sec}$. The exercise "tilting torso forward from sitting position" represented result 3,9cm among boys and 5,5cm among girls; the exercise "long jump from place" represented $14,7 \mathrm{~cm}$ among boys and $22,5 \mathrm{~cm}$ among girls; in the exercise "shuttle running" boys got result from 11,7 $\pm 1 \mathrm{sec}$ to $9,2 \pm 0,9 \mathrm{sec}$ and girls - from $12,1 \pm 1,2 \mathrm{sec}$ to $10,2 \pm 1 \mathrm{sec}$. What is more, positive and statistically important changes $(p<0,05)$ where in results of pupils' psycho-emotional condition evaluation. We have noticed increasing in levels of well-being, activeness, mood.
\end{abstract}

Keywords: physical education, junior schoolchildren, aerobics. 


\section{Introduction}

The modern educational system today is inextricably linked with physical education, as an essential component in the formation of a fully developed personality. One of the most important periods in the process of a person's development is junior school age, because at that age, the foundation of health, development of physical and mental qualities, motor activity, ground of a healthy lifestyle is laid and strengthened.

The educational process of elementary school today is increasingly overloaded with subjects that develop only mental faculties, and at the same time does not take into account the decline in the level of physical development of modern children, the deterioration of their health. At the same time, it is fashionable to introduce innovations in education and upbringing, but they have little to do with the field of physical education, which enhances the already critical health condition of schoolchildren. (Moskalenko, 2009; Krusevich, 2010; Bodnar et al., 2016).

As the scientists point out, innovative technologies in the physical education of junior schoolchildren (Bodnar et al., 2015; Bodnarchuk et al., 2018;) are one of the possible ways of optimizing the physical education of the young generation. Recently some aerobics techniques, which are recommended to use in physical education of children of all ages have appeared in the practice of physical education, because they are aimed at increasing the level of health, physical fitness, mental faculties, forming a culture of personality and ideas about a healthy lifestyle, interest in exercises and serve as a prevention of various diseases.

The methodology and concrete ways to increase the efficiency of physical education system for children of elementary school age are carried out in the following directions: improvement of standard base (Sorokolit, 2017); development of the physical education system concept (Moskalenko, 2009); the development of the need for motor activity, increasing the adaptive capacity and the personal physical culture of schoolchildren is researched in the works of Ognistij, 2010; Butenko et al., 2017; Bodnarchuk et al., 2018). The questions of healthy lifestyle, development of physical and mental qualities touched upon in the works of Vilchkovsky, 2004; Moskalenko, 2018. The application of different forms of physical education is disclosed in the works of Weinberg, Gould, 2003; Sacheck \& Hall, 2014; Sarkauskiene, 2019. Some aspects of the theoretical substantiation of various means of aerobics for children can be found in the works of domestic and foreign authors (Hawley \& Franks, 2000; Starchenko, 2014).

However, the problem of the search and scientific substantiation of the use of aerobics for children in the educational process of junior pupils, which corresponds to the methodological requirements adopted in the theory and practice of physical education, is still relevant. 
The purpose of the work was to discover the influence of fitness tools on physical development, physical preparation, psycho-emotional condition on younger school-age pupils.

\section{Methodology}

In the research such methods as analysis and special researches and methodological literature synthesis; anthropometrical methods; method of psycho-emotional diagnostics (WAM); pedagogical testing; physiological methods; pedagogical experiment; methods of mathematical statistics were used. In order to determine physical development indicators of 9-years-old pupils in the research were conducted anthropometrical evaluations such as body length (BL) and bode weight (BW), that represent the level of morphological specifics. What is more, length-weight Kettle index was calculated in the research. The index of Ruffier Dickson was used for evaluating pupils' physical efficiency. It was made by measuring heart beating in calm situation, in first $15 \mathrm{sec}$ after exercising and last $15 \mathrm{sec}$ from the first minute after exercising. For measuring level of physical preparation such activities as " $30 \mathrm{~m}$ run", "tilt of the torso forward with sitting position", "long jump from place" and "shuttle running 4x9m". In order to evaluate phyco-emotional condition we have applied generally accepted methodic of operative evaluating of well-being, activity and mood (WAM). WAM is a chart containing 30 pairs of opposite characteristics, reflecting the studied features of the psycho-emotional condition (condition of health, activity, mood). Children, in the presence of a psychologist, were asked to select in each pair the characteristics that most closely corresponded to their condition, and to indicate the figure corresponding to the degree (strength) of the expressiveness of this characteristic. The total number of points in each of the criteria was within the range of 10-70. Estimates exceeding 40 points showed a favorable state of the children and can be evaluated as an average; below 40 points is considered as an unfavorable condition and, accordingly, a poor rating of their own condition, Estimates that were in the range of 50 points and above evidenced - a high grade of their own condition.

The results were processed by mathematical statistics methods. The pedagogical experiment was conducted in Lviv secondary school I-III level № 66 and in Lviv specialized school I-III levels with foreign languages deep learning № 45. Pupils from third forms have taken part in the experiment. In the research 82 pipls have taken part, among them were 42 boys and 40 girls. The actual age of all pupils was 9 years old in the beginning of the experiment. 


\section{Results}

The hypothesis about positive influence of children fitness tools on physical development indicators, physical preparation and psycho-emotional sphere of 9-years-old pupils become the basis of elaborating and implementing author methodic in the process of physical education in elementary school. The evaluation of effectiveness of the author program war measured by conducting pedagogical experiment during 2017-2018 studying years.

To implement the research plan, the most interesting, emotional and effective means of aerobics for children were chosen: game aerobics, animal aerobics and game stretching. Animal aerobics involves the implementation of general development exercises to music with simulation, imitation of various animals' movements with the simultaneous pronunciation of sounds, recitation of poems, the performing of songs. Game aerobics includes an exercise combination of games of different intensity (active games, sports games, folk games, fun, relay race) to musical accompaniment. The implementation of the means of aerobics for was carried out in combination with the use of innovative approaches in conducting physical education lessons: a lesson-game, a lesson-fairy tale, a lesson-trip, a lesson-competition.

Systematization and generalization of the library and e-resources allowed forming the purpose of the lessons using the means of game aerobics, animal aerobics and game stretching, which was to improve the level of physical development, physical fitness and emotional state of junior pupils. Based on the purpose of the program, the main provisions of the program were clearly defined: adequacy of the load according to the individual characteristics of the pupils; using exercises of low intensity, increasing the heart rate by $20-30 \%$ from the initial state at the preparatory stage; creation of optimal conditions for stimulation of the cardiovascular and respiratory system activity at loads of $40-50 \%$ intensity from the maximum oxygen consumption (at heart rate 140-155 beats per minute); use of high and moderate intensity exercises at the main stage; gradual increase in the load, due to the increase in the volume of exercises, and in the future due to the gradual increase in the intensity of exercises.

The program was developed for a period of 6 months (70 classes) and was divided into two stages: preparatory (10 classes) and basic (60 classes). Task of the preparatory stage: to familiarize children with the basic concepts of game aerobics, animal aerobics and game stretching; teach the games rules and the main motor actions accompanying songs and recitatives; to raise the interest of children in exercising. Task of the main stage: to improve the level of physical condition of students through the use of means of game aerobics and animal aerobics, the content of which includes aerobic and respiratory exercises that have a positive effect on the functioning of the cardiovascular and respiratory system of the body; 
to improve the level of physical fitness with the help of means of animal aerobics and game aerobics, which promote development of speed, strength and coordination qualities and means of game stretching aimed at development of flexibility; to raise a steady interest in classes through the use of role-playing, game elements and musical accompaniment during lessons.

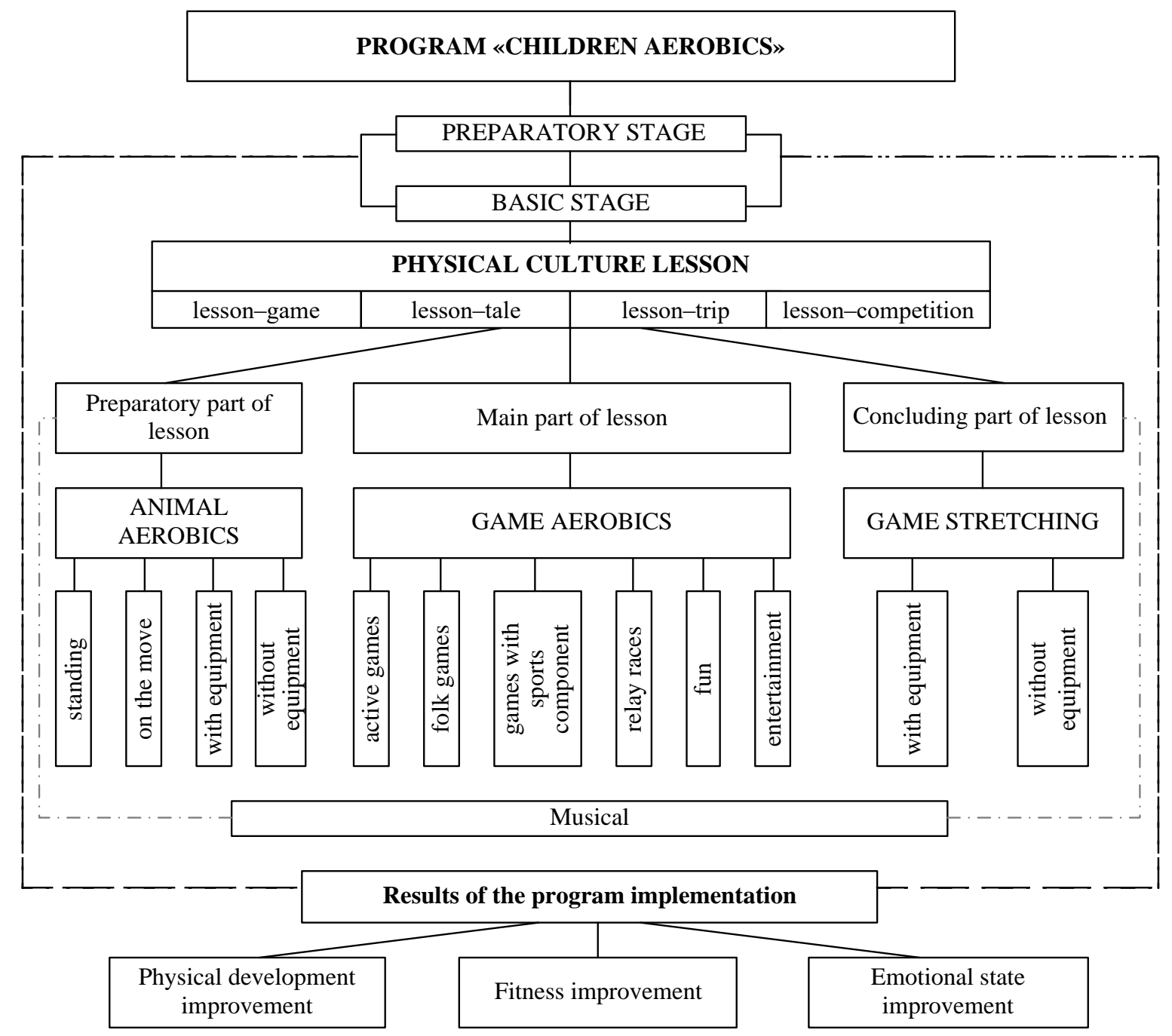

Figure 1 Scheme of «Children Aerobics» program implementation

At each lesson, the means of game aerobics, animal aerobics and game stretching were combined (Fig. 1). The preparatory part of the lesson included the use of means of animal aerobics, which was carried out in the form of aerobic simulation exercises staying at place and in motion with a variety of sports equipment (balls, sticks, hoops, dumbbells, ribbons, fit-balls) to musical accompaniment. Means of animal aerobics used to prepare the body for the main part of the lesson, as well as for the prevention of posture defects, flat feet. The music pace in the preparatory part was mostly moderate. In the main part of the 
lesson included exercises aimed at the formation of motor skills and game aerobics. Means of game aerobics included: active and folk games, games with elements of sports (basketball, badminton, volleyball, tennis and football), relay and fun. The preference was given to games of high and moderate intensity to musical accompaniment. The music pace of the main part was mostly fast and very fast. The final part included the means of game stretching aimed at stretching, relaxing tense muscles, restoring and bringing to normal the functional and mental parameters. Complexes of exercises were performed with and without special equipment at a slow pace to music.

Junior pupils' physical fitness is very important while optimizing the process of physical education. The analysis of the pupils' physical fitness results according to the Kettle index shows that more than half of the children (54.4\%, $60.2 \%$ ) have an average level of physical fitness before the experiment, one third of them $(25.7 \%, 28.7 \%)$ have a low level and only $(14.1 \%, 16.9 \%)$ showed a high level of physical development (Fig. 2).

In the experimental and control groups, the data of physical fitness of pupils at the beginning of the pedagogical experiment did not differ $(t=0.061, \mathrm{p}>0.05)$.

As a result of the experimental method influence, there is an improvement in the indices of children physical fitness by the Kettle index in pupils of control and experimental groups, which is natural, as all the children attended physical education lessons. However, in the experimental group pupils, there is a significant improvement in the results of physical development before and after the experiment, in particular the high level (from 16.9\% to $43.1 \%$ ) and the decrease in the average (from 54.4 to $46.8 \%$ ), and especially low level of physical development (from 28.7 to $10.1 \%$ ) ( $\mathrm{p}<0.05$ ). Instead, in the control group pupils, no such significant changes were observed $(\mathrm{p}>0.05)$.

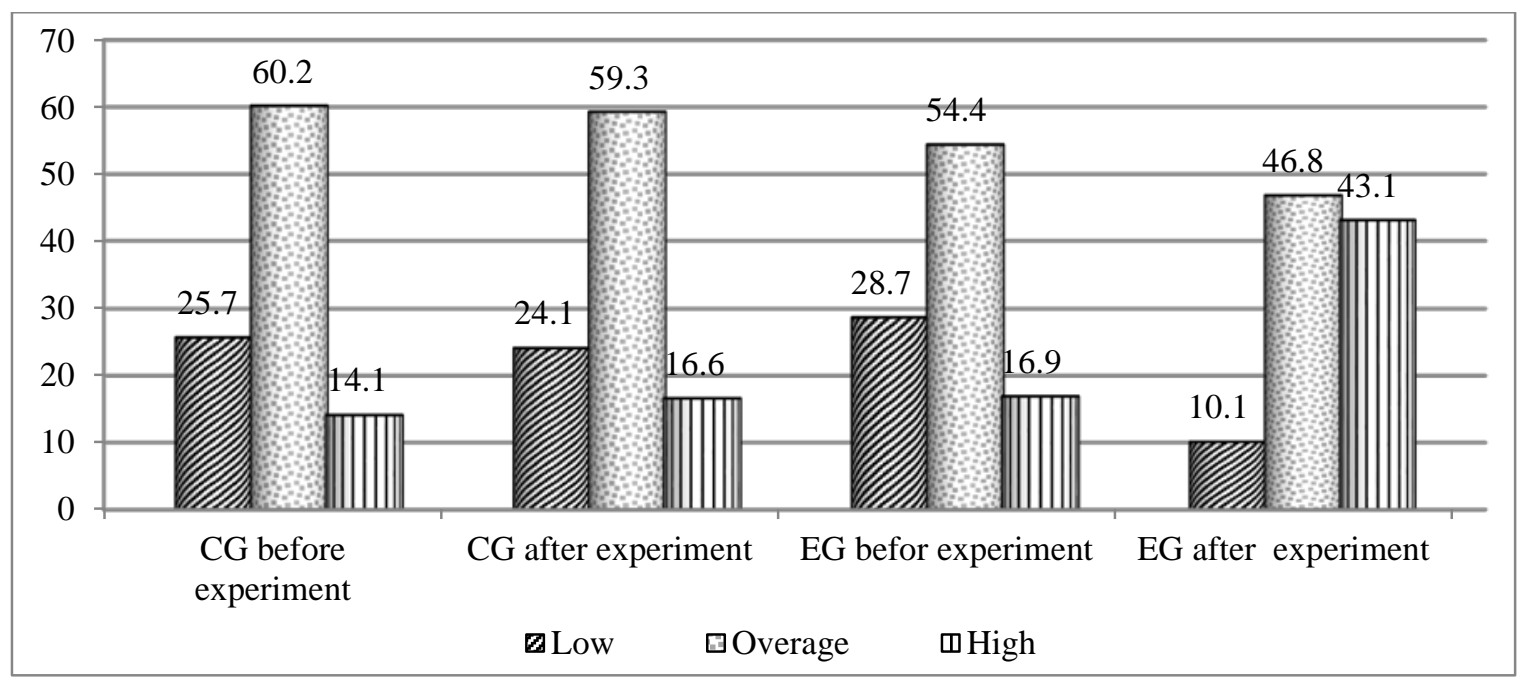

Figure 2 Indices of physical fitness by Kettle index, \% $(n=82)$ 
Positive changes also occurred in the results according to the Ruffier Dickson's test in both experimental and control groups, due to the physiological development of a child's body (Table 1).

Table 1 Levels of cardiovascular system functional status according to Ruffier Dickson index, \% $(n=82)$

\begin{tabular}{|lcccc|}
\hline \multirow{2}{*}{ Levels } & \multicolumn{2}{c}{ CG } & \multicolumn{2}{c|}{ EG } \\
\cline { 2 - 5 } & before & after & before & after \\
\hline High & 0 & 0 & 0 & 0 \\
Above average & 5.2 & 5.4 & 4.8 & 14.1 \\
Average & 52.7 & 55.8 & 51.3 & 69.2 \\
Below average & 37.1 & 36.2 & 38.4 & 16.7 \\
Low & 5.0 & 2.6 & 5.5 & 0 \\
\hline
\end{tabular}

Notes: EG-experimental group, $C G$-control group

However, there is a significant improvement in the result $(\mathrm{p}<0.05)$ only in the experimental group pupils. Thus, as a result of the implementation of the pilot program, there was a decrease in the indices below the average level (from $38.4 \%$ to $16.7 \%$ ), growth in the indices above the average level (from $4.8 \%$ to $14.1 \%$ ), and indices of low level were not detected at all. The obtained results testify to the effectiveness of the author's methodology, since it included a number of aerobic exercises, as well as games and breathing exercises (poems, songs, recitatives) of certain dosage, volume, and intensity) that the pupils did during lessons which included aerobics for children. Unfortunately, it is necessary to note the fact that none of the research groups shows a high level, which depends to a large extent on the children's lifestyle, that is an area for further research.

Positive changes in the results of the junior pupils' physical fitness level in the experimental group $(\mathrm{p}<0.05)$ in the conditions of the pedagogical experiment were found (Table 2). The indicator in control classes increased for $0.3 \mathrm{sec}$ among boys and for $0.4 \mathrm{sec}$ among girls in the test exercise " $30 \mathrm{~m}$ Run" after the experiment was finished. The crucial growth was noticed among experimental classes, in particular both girls and boys got result higher for $0.8 \mathrm{sec}$.

After the exercise «tilt of the torso forward from sitting position» in the control group, the index increased in the boys by $1.3 \mathrm{~cm}$, in girls - by $2.4 \mathrm{~cm}$, and in the experimental group by $3.9 \mathrm{~cm}$ and $5.5 \mathrm{~cm}$, respectively. In the experimental group significantly increased the index after the test exercise, «Long jump», so that the boys demonstrated an improvement of $14.7 \mathrm{~cm}$, the girls $-22.5 \mathrm{~cm}$, whereas in the control group such significant changes did not occur. After the test exercise «Shuttle running $4 \times 9 \mathrm{~m}$ » there was a similar tendency in favor of the experimental group. 
Rymar et al., 2020. Tools for Children Fitness in the Physical Education of Primary School Pupils

Table 2 Indices of junior pupils' physical fitness, $(n=82)$

\begin{tabular}{|c|c|c|c|c|c|c|c|}
\hline \multirow{2}{*}{ Test } & \multirow{2}{*}{ Sex } & \multicolumn{2}{|c|}{ Control group } & \multicolumn{2}{|c|}{ Experimental group } & \multicolumn{2}{|c|}{$t_{\mathrm{CG}-\mathrm{EG}}$} \\
\hline & & before & after & before & after & before & after \\
\hline Running $30 \mathrm{~m}$ & boys & $6.4 \pm 0.5$ & $6.1 \pm 0.4$ & $6.2 \pm 0.7$ & $5.4 \pm 0.5$ & 0.05 & 0.03 \\
\hline (sec) & girls & $6.8 \pm 0.5$ & $6.4 \pm 0.4$ & $6.9 \pm 0.5$ & $6.1 \pm 0.5$ & 0.05 & 0.04 \\
\hline Tilt the torso & boys & $3.3 \pm 3.4$ & $4.6 \pm 3.1$ & $3.5 \pm 4.2$ & $7.4 \pm 4.6$ & 0.05 & 0.04 \\
\hline $\begin{array}{l}\text { forward from } \\
\text { sitting position } \\
(\mathrm{cm})\end{array}$ & girls & $7.5 \pm 5.2$ & $9.9 \pm 5.6$ & $7.2 \pm 4.4$ & $12.7 \pm 4.5$ & 0.05 & 0.02 \\
\hline Long jump & boys & $135.2 \pm 12.0$ & $143.5 \pm 13.9$ & $140.1 \pm 17.5$ & $154.8 \pm 14.2$ & 0.05 & 0.04 \\
\hline from place $(\mathrm{cm})$ & girls & $123.1 \pm 16.3$ & $129.8 \pm 16.7$ & $127.3 \pm 12.3$ & $149.8 \pm 15.8$ & 0.05 & 0.03 \\
\hline «Shuttle» & boys & $11.9 \pm 1.0$ & $10.2 \pm 1.0$ & $11.7 \pm 1.0$ & $9.2 \pm 0.9$ & 0.05 & 0.03 \\
\hline $\begin{array}{l}\text { running } 4 \times 9 \mathrm{~m} \\
(\mathrm{sec})\end{array}$ & girls & $12.6 \pm 1.3$ & $10.9 \pm 1.1$ & $12.1 \pm 1.2$ & $10.2 \pm 1.0$ & 0.05 & 0.01 \\
\hline
\end{tabular}

Thus, after completing the experiment, the difference between the indices in the experimental and control groups was: running $30 \mathrm{~m}-$ boys $-0.7 \mathrm{~s}$, girls $0.3 \mathrm{~s}$; tilting of the torso forward from sitting position - boys $-2.8 \mathrm{~cm}$, girls - also $2.8 \mathrm{~cm}$; long jump - boys $-11.3 \mathrm{~cm}$, girls $-20.0 \mathrm{~cm}$; «shuttle» running $4 \times 9 \mathrm{~m}-$ boys $-1.0 \mathrm{~s}$, girls $-0.7 \mathrm{~s}$. The children, who studied under the experimental program, achieved significantly higher results $(\mathrm{p}<0.05)$ compared with the control group in four types of the test exercises.

The analysis of the obtained results allowed us to establish that the change of indices in the experimental group pupils, in relation to the pupils of the control group, is characterized by a high level of statistical probability $(\mathrm{p}<0.05)$, which confirms previous studies of scientists about the sensitive period of development of these qualities in children aged nine and causes the need for additional focus on the development of important, vital physical qualities of junior pupils.

The research revealed the influence of the author's program on the psychoemotional state of children as well, the evaluation of which was carried out using the method of determining the state of well-being, activity, and mood (WAM). After the experiment, we can state that in the experimental group pupils, the indices of emotional state, namely the state of well-being, activity and mood increase towards a favorable high level $(\mathrm{p}<0.05)$ (Table 3). Thus, in the experimental group pupils, after an experiment, a high (favorable) level of wellbeing increased from $51.2 \%$ to $55.3 \%$, the average (norm) level - from $30.3 \%$ to $36.1 \%$, and a decrease in the low (unfavorable) level - from $18.5 \%$ to $8.6 \%$. A similar tendency is observed in the state of activity: the growth of a high level in the experimental group occurred from $51.5 \%$ to $57.6 \%$, the average - from $29.1 \%$ to $34.2 \%$ and a decrease in the low level - from $19.4 \%$ to $8.2 \%$. As for mood, we also state the growth of the high level from $60.2 \%$ to $69.3 \%$, the average level - from $26.3 \%$ to $28.1 \%$, and a significant decrease in the low level of 
SOCIETY. INTEGRATION. EDUCATION

Proceedings of the International Scientific Conference. Volume III, May $22^{\text {th }}-23^{\text {th }}, 2020.540-551$

mood - from $13.5 \%$ to $2.6 \%$. Instead, in the control group there were no positive changes at all.

Table 3 Indices of junior pupils psycho-emotional state, \% $(n=82)$

\begin{tabular}{|c|c|c|c|c|c|c|c|c|c|c|c|}
\hline \multirow{3}{*}{$\begin{array}{l}\text { Levels of } \\
\text { emotional } \\
\text { state }\end{array}$} & \multicolumn{4}{|c|}{ Well-being } & \multicolumn{4}{|c|}{ Activity } & \multicolumn{3}{|c|}{ Mood } \\
\hline & \multirow{2}{*}{\multicolumn{2}{|c|}{$\begin{array}{l}\text { CG } \\
\text { before after }\end{array}$}} & \multirow{2}{*}{\multicolumn{2}{|c|}{$\begin{array}{l}\text { EG } \\
\text { before after }\end{array}$}} & \multirow{2}{*}{\multicolumn{2}{|c|}{$\begin{array}{l}\text { CG } \\
\text { before after }\end{array}$}} & \multirow{2}{*}{\multicolumn{2}{|c|}{$\begin{array}{l}\text { EG } \\
\text { before after }\end{array}$}} & \multirow{2}{*}{\multicolumn{2}{|c|}{$\begin{array}{l}\text { CG } \\
\text { before after }\end{array}$}} & \multirow{2}{*}{$\begin{array}{l}\text { EG } \\
\text { before after }\end{array}$} \\
\hline & & & & & & & & & & & \\
\hline High & 49.1 & 47.2 & 51.2 & 55.3 & 53.1 & 52.4 & 51.5 & 57.6 & 58.3 & 58.4 & $\begin{array}{ll}60.2 & 69.3\end{array}$ \\
\hline Average & 28.3 & 27.4 & 30.3 & 36.1 & 28.2 & 27.6 & 29.1 & 34.2 & 26.3 & 27.1 & $26.3 \quad 28.1$ \\
\hline Low & 22.6 & 25.4 & 18.5 & 8.6 & 18.7 & 20.0 & 19.4 & 8.2 & 15.4 & 14.5 & $13.5 \quad 2.6$ \\
\hline
\end{tabular}

Notes: EG - experimental group, CG - control group

In our opinion, the growth of the psycho-emotional state in the experimental group pupils was due to the introduction of interesting, non-typical, highemotional means, methods and interactive forms of conducting of physical culture lessons for junior schoolchildren who not only performed physical exercises, but also received positive emotional feelings and enjoyed motor activity.

Thus, it can be argued that the developed program with the use of aerobics for children in the process of physical education of junior pupils is effective and can be used to improve their physical development, psycho-emotional state and increase physical fitness of primary school children.

\section{Discussion}

Recently the educational load of pupils in general education schools has grown so much that caused by this low physical activity and restriction of muscular work becomes the cause of diseases of the organism's various systems (Moskalenko, 2009; Krusevich, 2010). The counteraction to the negative effects of limiting the motor activity of children is physical education and sports, which can be an important factor in the preservation and strengthening of health, comprehensive development, improvement of efficiency and reduction of fatigue, increase of resistance of the organism to various diseases during the period of study (Bodnar et al., 2015; Dubogai, 2017). The system of physical education at the school is aimed at the comprehensive implementation of a wide range of recreational, educational and educational tasks, respectively, it is relevant to find adequate means and methods to achieve the goals (Butenko et al., 2017; Bodnarchuk et al., 2018). One of the ways to optimize physical education is to introduce in the process of physical education aerobic technologies for children that are aimed at increasing the level of health, physical fitness, mental faculties, forming a person's ideas about a healthy lifestyle (Saykina, 2009; Starchenko, 2014). 
The results of our research were confirmed and supplemented by scientists' well-known developments from this particular sphere (Vilchkovsky, 2004; Kozina et al., 2007; Palchuk, 2012; Tomenko, 2013; Pangeleva, 2017; Moskalenko, 2018).

As a result of application of the author's program using the means of children aerobics in the experimental group, the functional parameters by Ruffier Dickson index and the results of physical development according to Kettle index have significantly improved. The obtained results prove the positive influence of the developed method. The combination of aerobic and respiratory exercises improves the functioning of the cardiovascular and respiratory systems, and allows pupils to balance the weight-growth indices in accordance with individual standards.

After the pedagogical experiment, there was an improvement in the level of indices of physical fitness in the experimental and control groups, which is a consequence of the biological development of the organism and directed pedagogical influence. The use of aerobics for children of different intensity contributes to the improvement of the indices of overall endurance, flexibility, agility, speed and strength qualities, which is confirmed by significantly higher results of physical fitness and functional test in the experimental group pupils.

The obtained results showed that the implementation of the developed program positively influenced the psycho-emotional state of the children in the experimental group, which is important, as one of the main tasks of physical education is to increase the motivation and developing a stable interest in physical exercises. Conducting classes to musical accompaniment, introduction of interesting, non-typical, high-emotional exercises, game method and innovative approaches to the lesson: lesson-game, lesson-fairy tale, lesson-trip, and lessoncompetition have positively influenced the indices of well-being, activity and mood of pupils during the pedagogical experiment. The developed program of the use of aerobics for children allows solving the problems of physical education for pupils of junior school age, first of all, strengthening of health, providing of harmonious development of an organism, increase of physical fitness level taking into account favorable periods of development of children's physical qualities and increase of motivation for motor activity.

\section{Conclusions}

There is a discrepancy between the ever-greater need for a healthy lifestyle in schoolchildren and the real content of education and upbringing; the need to introduce innovative technologies for the preservation and strengthening of children's health and the lack of research in this area; the popularity of aerobics 
technologies in the system of physical education and the scanty scientific substantiation of the use of aerobics in the educational process of children.

The developed program with the use of aerobics for children was aimed at improving the level of physical development, physical fitness and psychoemotional state of junior schoolchildren and was divided into two stages. During physical education lessons, it was supposed to solve the following tasks: to improve the level of children's physical fitness through the use of game aerobics and animal aerobics, the content of which includes aerobic and respiratory exercises that have a positive effect on the functioning of the cardiovascular and respiratory system of the body; to improve the level of physical fitness with the help of animal aerobics and game aerobics, which promote development of speed, strength, and coordination qualities, and game stretching aimed at development of flexibility; to raise a steady interest in exercising through the use of roleplaying, game elements and musical accompaniment during the lessons.

As a result of the introduction of aerobics for children in the process of physical education in the experimental group, there was a significant improvement in the results of physical development, according to Kettle index, in particular, a high level (from $16.9 \%$ to $43.1 \%$ ) and a decrease in the average (from 54.4 to $46.8 \%$ ) and especially low level of physical development (from 28.7 to $10.1 \%)$ ( $\mathrm{p}<0.05$ ). Probably positive changes occurred according to Ruffier Dickson test results $(\mathrm{p}<0.05)$, namely, improving the above average level (from 4.8 to $14.1 \%$ ), a decrease in lower than the average level (from 38.4 to $16.7 \%)$.

The analysis of the physical fitness results showed that in the experimental group the indicators of the test exercise «30 m run» were significantly improved. Among boys results were from $6.2 \pm 0.7 \mathrm{sec}$ to $5.4 \pm 0.5 \mathrm{sec}$, among girls - from $6.9 \pm 0.5 \mathrm{sec}$ up to $6.1 \pm 0,5 \mathrm{sec}$; «Tilt the body forward from sitting position»$3.9 \mathrm{~cm}$ among boys, and $5.5 \mathrm{~cm}$ among girls, «Long jump from place» - boys got result $14.7 \mathrm{~cm}$, girls $-22.5 \mathrm{~cm}$, «Shuttle running $4 \times 9$ m»- boys' results are from $11.7 \pm 1.0 \mathrm{sec}$ to $9.2 \pm 0.9 \mathrm{sec}$, girls' - from $12.1 \pm 1.2 \mathrm{sec}$ to $10.2 \pm 1.0 \mathrm{sec}$.

The results of the study showed that due to the influence of the author's program the psycho-emotional state $(p<0.05)$ (well-being, activity, and mood) of the experimental group was significantly improved: the indices of high level as for well-being increased from $51.2 \%$ to $55.3 \%$; activity - from $51.5 \%$ to $57.6 \%$; mood - from $60.2 \%$ to $69.3 \%$

Consequently, the above results of the study prove the effectiveness of the implementation of the program that includes aerobics for children and can be recommended for optimization of the physical education of junior schoolchildren. 
Rymar et al., 2020. Tools for Children Fitness in the Physical Education of Primary School Pupils

\section{References}

American Alliance for Health, Physical Education, Recreation and Dance. (2005). Physical education for lifelong fitness: the Physical Best teacher's guide. Champaign, IL: Human Kinetics.

Bodnar, I., Petryshyn, Y., Solovei, A., Rymar O., Lapychak, I., Shevtsiv, U., Ripak, M., Yaroshyk, M., \& Sorokolit, N. (2016). Health complaints and well-being complaints among secondary school children. Journal of physical education and sport, 16(3), 905-909.

Bodnar, I., Rymar, O., Solovey, A., \& Datskiv, P. (2015). Objective criterias for determining the functional-reserve opportunities of middle-school-age pupils. Pedagogy, psychology and medical and biological problems of physical education, 11, 11-19.

Bodnarchuk, O., Rymar, O., \& Solovey, A. (2018). Interaction of school and family in physical education of first grade pupils. Journal of physical education and sport, 18(2), 1092-1098.

Butenko, H., Goncharova, N., \& Saienko, V. (2017). Physical condition of primary school children in school year dynamics Department of Theory and Method Published. Journal of Physical Education and Sport, 21(2), 543-549.

Hawley, E., \& Franks, B. (2000). Health-Related Aerobics. 367. Kyiv.

Krutsevych, T., \& Bezverkhnya, G. (2010). Recreation in physical culture of different population groups. Kyiv.

Moskalenko, N.V. (2009). Theoretical and methodological foundations of innovative technologies in the system of physical education of younger students ("Physical culture, physical education of different population groups"): author. diss. of the Doctor of Science in Physical education and sport. 42. Kyiv.

Ohnystyj, A. (2010). Theoretical and methodical principles of preschool children' physical education. 132 Ternopil.

Sacheck, J.M., \& Hall, M. (2014). Current Evidence for the Impact of Physical Fitness on Health Outcomes in Youth. American Journal of Lifestyle Medicine, 2. DOI: https://doi.org/10.1177/1559827614537780

Sarkauskiene, A., Noble, B., \& Kardeliene, L. (2019). Non - formal physical education influence on health related physical fitness of children. Society. Integration. Education. Proceedings of the International Scientific Conference. IV, 252-267. DOI: http://dx.doi.org/10.17770/sie2019vol4.3865

Sorokolit, N., Shyan, O., Lukjanchenko, M., \& Turchyk, I. (2017). Improvement of 5-9th grades schoolchildren physical education in ukraine by using variable modules curriculum. Journal of Physical Education and Sport, 17(4), 2110-2115.

Starchenko, A.Y. (2014). Children's fitness as one of the effective ways of improving the health and physical education of preschool-age children. Pedagogical sciences: theory, history, innovative technologies, 2(36), 177-184.

Weinberg, R., \& Gould, D. (2003). Foundations of sport \& exercise psychology: third edition. Human Kinetics. 